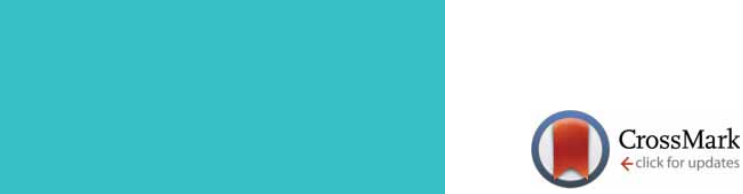

\title{
Key paediatric messages from Amsterdam
}

\author{
Jonathan Grigg ${ }^{1}$, Jürg Barben², Kajsa Bohlin ${ }^{3}$, Mark L. Everard ${ }^{4}$, Graham Hall ${ }^{5}$, \\ Mariëlle Pijnenburg ${ }^{6}$, Kostas N. Priftis $^{7}$, Franca Rusconi ${ }^{8}$ and Fabio Midulla ${ }^{9}$
}

Affiliations: ${ }^{1}$ Centre for Child Health, Blizard Institute, Queen Mary University of London, London, UK. ${ }^{2}$ Division of Paediatric Pulmonology, Children's Hospitals of Eastern Switzerland, St. Gallen, Switzerland. ${ }^{3}$ Division of Pediatrics, Karolinska University Hospital, Stockholm, Sweden. ${ }^{4}$ School of Paediatrics and Child Health, The University of Western Australia, Crawley, Australia. ${ }^{5}$ Telethon Kids Institute, Subiaco, Australia. ${ }^{6}$ Dept of Pediatric Respiratory Medicine, Erasmus MC - Sophia Children's Hospital, Rotterdam, The Netherlands. ${ }^{7}$ Children's Respiratory and Allergy Unit, Third Dept of Paediatrics, "Attikon" Hospital, University of Athens Medical School, Athens, Greece. ${ }^{8}$ Unità di Epidemiologia, AOU Meyer, Florence, Italy. ${ }^{9}$ Dipartimento di Pediatria e Neuropsichiatria Infantile, Ospedale Policlinico Umberto I, Rome, Italy.

Correspondence: Jonathan Grigg, Centre for Child Health, Blizard Institute, Queen Mary University of London, 4 Newark Street, London, E12AT, UK. E-mail: J.griggaqumul.ac.uk

ABSTRACT The Paediatric Assembly of the European Respiratory Society (ERS) maintained its high profile at the 2015 ERS International Congress in Amsterdam. There were symposia on preschool wheeze, respiratory sounds and cystic fibrosis; an educational skills workshop on paediatric respiratory resuscitation; a hot topic session on risk factors and early origins of respiratory diseases; a meet the expert session on paediatric lung function test reference values; and the annual paediatric grand round. In this report the Chairs of the Paediatric Assembly's Groups highlight the key messages from the abstracts presented the Congress.

@ERSpublications

Paediatric highlights of the 2015 ERS International Congress http://ow.ly/10iBsz

Received: Feb 122016 | Accepted: March 282016

Conflict of interest: Disclosures can be found alongside this article at openres.ersjournals.com

Copyright $\odot$ ERS 2016. This article is open access and distributed under the terms of the Creative Commons Attribution Non-Commercial Licence 4.0. 


\section{Early life risk factors for wheezing and asthma}

There is increasing interest in exposure during pregnancy and even prior to conception on the risk of childhood respiratory diseases [1]. LODGE et al. [2] investigated the association between grand-maternal smoking at 10-12 weeks of pregnancy and asthma risk in grandchildren using data from Swedish registries. Children had a $6-22 \%$ increased risk of asthma during the first 6 years of life if their grandmothers smoked during early pregnancy, independent of maternal smoking. These findings support possible epigenetic transmission of risk from environmental exposures in previous generations. In a cross-sectional study, PESCE et al. [3] reported that children exposed to maternal vaginitis in pregnancy were more likely to have had bronchitis, pneumonia and wheezing in the first 2 years of life, and current asthma at 6 years of age. However, as the researchers themselves acknowledge, these data should be confirmed in a prospective study in order to avoid recall bias and misclassification. Use of paracetamol in pregnancy has been repeatedly reported to be associated with wheezing and asthma in the first years of life [4], but the problem of confounding by indication has also been raised [5]. MAGNus et al. [6] explored the issue in the Norwegian Mother and Child Cohort and concluded that although there is evidence of confounding by indication this does not fully explain the association between paracetamol use only during pregnancy and asthma at 3 and 7 years of age in the offspring. As for early post-natal factors associated with wheezing and asthma, living on farms has been shown to protect children from asthma and allergies. A major factor involved in this effect is the consumption of unprocessed cow's milk [7]. Within the Pasture Study Group, which includes children living in rural areas in five European countries, samples of the milk usually consumed were taken at the age of 4.5 years [8], while doctor-diagnosed asthma was parent-reported at age 6 years. The risk of asthma was reduced when consuming raw farm milk as compared with shop milk. Part of the effect was attributable to the content of omega- 3 fatty acids, which could counterbalance the synthesis of pro-inflammatory leukotrienes and prostaglandins. Accumulating evidence suggests an association between early growth patterns and wheezing in infancy. Within the NINFEA birth cohort, Popovic et al. [9], using a novel modelling approach (SITAR) that allows for mutual adjustment of different aspects of growth, showed that larger size and faster growth over the first 18 months of life, but not the timing of peak weight velocity, were independently associated with an increased risk of wheezing at 18 months of age.

\section{Asthma and allergy: genetics and environment}

The asthma risk locus 17q21 modifies the effects of smoking and early viral infections on subsequent asthma [10]. Loss et al. [11] of the Pasture Study Group followed children in rural areas of several countries in Europe from birth until 6 years of age. Single nucleotide polymorphisms (SNPs) in the genes ORMDL3 and GSDMB at locus 17q21 were assessed in cord blood. Exposures to siblings or to animal sheds affected wheezing largely in carriers of known asthma risk alleles. Loss et al. [11] conclude that the 17q21 locus might be related both to environmental susceptibility and to progression from wheeze to asthma. The associations between traffic-related air pollution (TRAP), asthma and allergies in children are heterogeneous; possibly due to genetic polymorphisms that modify the response to oxidative stress [12]. BOWATTE et al. [13] investigated if variants in the glutathione pathway alter associations between early life TRAP exposure and childhood asthma and allergies in a high risk birth cohort of children in Australia. Baseline TRAP exposure was not associated with any outcome. Carriers of GSTM1null and GSTT1null had an increased risk of current asthma at 7 years and current eczema at 18 years of age. GSTT1null carriers exposed to TRAP in early life had an increased risk of wheeze and asthma at 12 years of age when compared with TRAP exposed carriers of wild-type GSTT1. Polymorphisms of CD14 are associated with a lower risk of allergic disease in children, but little is known about the effects in adult life. LAU et al. [14] aimed to examine if the association between CD14 polymorphisms and allergic sensitisation in middle age was modified by sibling exposure in early life in participants from the Tasmanian Longitudinal Health Study. Exposure to siblings at 6 months, 2 years and 4 years was associated with a significantly reduced risk of allergic sensitisation. They showed evidence of CD14 SNPs and sibling interaction for allergic sensitisation. The gene-environment interaction was strongest in the first 6 months of life, suggesting that this may be a critical period for altering the risk of allergy.

\section{European Respiratory Society task force on primary ciliary dyskinesia and beyond}

Published data on primary ciliary dyskinesia (PCD), a rare disease leading to chronic airways inflammation and infection, are scarce and often based on small case series. A consensus statement of a European Respiratory Society (ERS) task force published in 2009 [15] concluded that the evidence base for diagnosis and treatment of PCD is poor and more research is needed. Nasal nitric oxide (nNO) is currently recommended as a screening tool. PANAJOTIs et al. [16] evaluated the diagnostic performance of nNO for detection of PCD by examining 12 published studies and concluded that it has high overall diagnostic accuracy. However, ColLINs et al. [17] using data from prospective referrals to the PCD service at University 
Hospital of Southampton, where the incidence of PCD is $11 \%$, underlined that the very high negative predictive value of the test $(99.1 \%)$ makes $\mathrm{nNO}$ a good rule-out test, but the low positive predictive value (26.3\%) makes it a poor test for general screening. They calculated that screening the general population would reduce the positive predictive value to $0.04 \%$. Within the European project BESTCILIA, HALBEISEN et al. [18] compared the lung function (forced expiratory volume in $1 \mathrm{~s}$ (FEV1)) of patients with PCD to the Global lung function initiative (GLI) 2012 reference values and to published data from UK patients with cystic fibrosis (CF) [19]. FEV1 was significantly reduced compared with normal reference values. As for the comparison with CF data, FEV1 was similarly low in children (e.g. at age 6-9 years patients with PCD had a FEV 1 of $87 \%$ predicted, while in CF patients FEV1 was $90 \%$ ); while in adults aged $18-21$ years FEV 1 was better in PCD (76\% predicted, 95\% CI 73-80\%) than in CF (66\% predicted, 95\% CI 65-68\%).

\section{Infant lung function}

Objectively assessing lung function in infants remains one of the most challenging aspects of respiratory physiology. For the most part measurements are performed following sedation, use complex equipment and require highly trained staff $[20,21]$. A recent survey on the clinical utility of infant lung function testing shows that while many centres were using lung function tests in infants to aid in clinical decision making there were many barriers to practical use [22]. One of these barriers was the availability of appropriate reference values for the infant version of spirometry (the raised volume rapid thoracic compression technique (RVRTC)). Lum et al. [23] reported reference values for modern commercial RVRTC equipment (Jaeger BabyBody; Care Fusion, San Diego, CA, USA) derived from data in 367 infants over 607 visits in four centres. Significant differences to the previously published RVRTC reference equations were noted [24], suggesting that users of the Jaeger BabyBody RVRTC equipment should adopt these new reference equations for their research and clinical RVRTC work.

Much of our understanding of lung growth and development has been derived from longitudinal measurements of lung function in birth cohorts $[25,26]$. However, the repeated measurement of infant lung function tests is difficult. KowALIK et al. [27] reported the feasibility of obtaining repeated multiple breath washout (MBW), body plethysmography and RVRTC data (in that order) over the first 2 years of life in the CHILD birth cohort. Of the three tests, MBW measurements had the highest feasibility at any one visit (range: 79-98\%), with body plethysmography (70-83\%) and then RVRTC (49-56\%) being successively lower. In the 191 infants that attended more than one visit, longitudinal data was obtained in $63 \%$ of MBW attempts compared with $50 \%$ of body plethysmography and 33\% of RVRTC assessments. These data suggest that feasibility will be influenced by test order, further highlighting the importance of consideration of the primary outcome in assessments of lung function in infancy. In a unique study, GRAY et al. [28] reported longitudinal measurements of infant lung function in the Drakenstein birth cohort. These investigators assessed lung function in unsedated infants at two time-points (6 weeks and 1 year). Of the 507 eligible infants, data was obtained in 472 (93\%) at 6 weeks and 377 (74\%) at 1 year for at least one lung function test. Paired tidal breathing or MBW outcomes were obtained in 234 and 209 infants, respectively, representing over $50 \%$ of the tested infants. These results demonstrate for the first time that unsedated measurements of some forms of infant lung function tests can be obtained longitudinally and may assist in allowing more wide spread integration of lung function testing in this age group.

\section{Lung function in older children}

PfLEGER et al. [29] compared changes in spirometry and multiple breath nitrogen washout after cold dry air challenge. In those children who had a positive challenge test the decrease in FEV1 and the increase in lung clearance index (LCI) correlated well. Scond (ventilation heterogeneity in conducting airways) was a predictor of airway hyperresponsiveness (AHR); exhaled nitric oxide fraction ( $F \mathrm{eNO}$ ) seemed to predict airway AHR as well. This might be helpful in assessing AHR in young children. De LEeUw et al. [30] showed that most children with asthma have normal spirometry, even if they have severe asthma. LCI had better discriminating power between severe and mild-to-moderate asthma; however, the vast majority of children had a normal LCI, irrespective of asthma severity, which may limit the clinical utility of MBW techniques in asthma. Two research groups reported data on a new lung function technique, structured light plethysmography (SLP) [31-33]. SLP is a noninvasive, noncontact test that does not require cooperation by the patient. It records real-time images of chest wall movement, using a grid of light on the chest and abdomen of the patient, which is imaged by two cameras. With this technique data on breathing pattern, the tidal breathing flow/volume graph, inspiratory or expiratory flow limitation, and regional subdivision may be assessed. A group from Verona, Italy showed that with SLP expiratory flow limitation could be detected in children with an acute asthma attack versus children with stable asthma [31]. Researchers from the UK assessed changes in tidal breathing parameters in children with acute asthma and found significant differences before and after bronchodilation [32]. The same group collected normative data on several parameters of SLP in healthy children [33]. This technique seems feasible in 
uncooperative children and as such may be useful in preschool children among others. It is obvious that more studies on validity, reproducibility and usefulness in clinical practice are needed.

The onset of disease, during which time pathophysiological changes are subtle, offers challenges for the identification and tracking of altered respiratory function in children. It is therefore imperative that the most appropriate lung function test for any one specific lung disease is selected [34]. NYILAs et al. [35] elegantly demonstrated this principle with an analysis of MBW outcomes in children with PCD, CF, preterm children and healthy controls. They demonstrated that even within one technique not all outcomes were altered. While preterm children tended to have normal MBW outcomes there were some differences in the slope III values when using the novel double tracer gas variant of the MBW test. In contrast, children with CF demonstrated altered lung clearance (LCI) and convection dependant ventilation distribution (Scond), while children with PCD also had altered acinar ventilation when compared with healthy children. Two studies reported longitudinal tracking of LCI and spirometry in children with CF, with both demonstrating that measurements of lung clearance were more likely to deteriorate over time than spirometry [36, 37]. While JAYASURIYA et al. [38] demonstrated that LCI was more likely to be abnormal (14 (58\%) out of 24 children) compared with FEV1 (5 (21\%) out of 24) in children following bone marrow transplant, further reinforcing the importance of using the most appropriate test for each specific lung condition. Several studies in children born preterm highlighted these concepts with varying degrees of pathophysiology reported. BAR-YISHAY et al. [39] reported spirometry and forced oscillatory mechanics before and after bronchodilator responsiveness in preterm children with and without bronchopulmonary dysplasia (BPD). As reported previously [40], preterm children exhibited reversible obstruction; however, the differences did not completely return to normal with lung function remaining lower in preterm compared with term born children. In contrast to other data presented at the Congress (discussed later), there were no differences in lung function between those children with and without BPD, which may be attributed to sample size and/or differences in cohort characteristics. O'DEA et al. [41] reported that while the majority of children (aged 9-11 years) born very preterm ( $<32$ weeks completed gestation) had altered lung structure on computed tomography (CT) this did not influence peak exercise capacity in these children, which was not different to that of term born controls. It was, however, noted that dynamic flow limitation during exercise was common in preterm children with BPD suggesting an altered response to maximal exercise unrelated to exercise capacity. The same children were followed longitudinally with paired lung function at 4-7 and 9-11 years [42]. As is commonly reported, preterm children with and without BPD had lower spirometry that term controls [40]. Spirometry was noted to decline over time only in preterm children with BPD with their mean \pm SD FEV1 reducing by $-0.47 \pm 0.92(\mathrm{p}<0.02) \mathrm{z}$-scores. The number of children with obstructive lung function (FEV1/forced vital capacity less than the lower limit of normal) increased from 32 to $52 \%$. The significance of these changes is not clear, but suggests an active disease process in preterm children with BPD that requires detailed investigation.

LCI measured by MBW has already been shown to be a sensitive marker of CF lung disease, which is now being be used as a surrogate outcome measure in clinical trials [43], as a surveillance tool to monitor structural lung disease [44], and as a prediction tool for pulmonary exacerbations in children with CF [45]. However, LCI response to therapy for pulmonary exacerbations is heterogeneous in CF patients, the overall effect size is small and the results are often discordant with FEV1 [46]. A group from Toronto presented their data on whether LCI can track disease progression: they observed an association between known risk factors (10 or more antibiotic courses and the use of dornase alfa) and higher LCI values; they also found better nutritional status was associated with lower LCI values [47]. An Australian group presented more evidence that LCI may be a useful surveillance tool for early lung disease, demonstrating LCI was higher in those with neutrophil activity in bronchoalveolar lavage (BAL), and in children infected with multiple pathogens compared with uninfected subjects [48]. The London CF Collaboration showed evidence that preschool LCI correlated with adolescent LCI $(\mathrm{r}=0.59, \mathrm{p}<0.01)$ and adolescent FEV1 $(\mathrm{r}=0.48$, $\mathrm{p}<0.05$ ), but there was no correlation between preschool and adolescent spirometry [49]. A comparison of exercise testing with MBW and high resolution CT showed a higher sensitivity than spirometry in detecting changes in CF lung disease [50]. However, there remain many open questions regarding the optimal equipment and standardisation, for example which software and algorithms should be used to calculate LCI and functional residual capacity from MBW [51, 52].

\section{Sleep monitoring}

The pathogenesis and treatment of sleep disorders in children are generally well understood; however, the optimal treatment of obstructive sleep apnoea (OSA) and the potential impact of comorbidities is less certain [53, 54]. Domany et al. [55] examined the rate of treatment failure in 659 children with moderate-to-severe OSA. Children were assessed for residual OSA using a screening questionnaire following either adenotonsillectomy, adenoidectomy or no treatment. Untreated children were twice as likely (OR 2.02, 95\% CI 1.26-3.51) to have ongoing OSA compared with children treated with 
adenotonsillectomy, while there were no differences between adenotonsillectomy and adenoidectomy suggesting that adenoidectomy may offer additional treatment pathways for paediatric OSA. While laboratory based sleep studies remain the gold standard for the diagnosis of sleep disorders, the cost and availability remain barriers to their use. Options that allow the screening of children to minimise the requirement for polysomnography (PSG) are urgently needed. VAN EYCK et al. [56] and WEBER et al. [57] reported the potential of screening in children with OSA. VAN EYCK et al. [56] assessed the ability to identify OSA in 130 obese children using nocturnal oximetry when compared with full PSG studies, and reported poor sensitivity (58\%) and specificity (88\%) of oximetry concluding that oximetry alone was insufficient to identify OSA in obese children. WEBER et al. [57] assessed the role of unattended PSG in 135 children over a 3-year period. Study failure was highest in the first year (52\%) and dramatically decreased to $15 \%$ in the third year. The primary cause of failure was loss of sensor, which occurred more commonly in younger children. While these data highlight the importance of training in these forms of studies, this study confirms the benefits of unattended PSG in subgroups of patients. While the assessment and treatment of airway inflammation is common in children with asthma, its role in children with sleep disorders is less clear [58]. Studies presented at the 2015 ERS International Congress reported increased 8-isoprostane [59] and leukotriene B4 [60] in children with OSA. SuPINO et al. [59] assessed 8-isoprostane from urinary and/or exhaled breath condensate samples and matched PSG in 84 children with sleep disordered breathing. Children with moderate-to-severe OSA had higher 8-isoprostane (median (interquartile range) 52.1 $\left.(39.2-100.6) \mathrm{pg} \cdot \mathrm{mL}^{-1}\right)$ than children with primary snoring only $\left(31(18.8-41.9) \mathrm{pg} \cdot \mathrm{mL}^{-1} ; \mathrm{p}<0.005\right)$ with significant associations between 8-isoprostane and the apnoea-hypopnoea index (AHI) in children with OSA. In contrast, Alexopoulos et al. [60] found no relationships between leukotriene B4 and the AHI $(\mathrm{r}=-0.11 ; \mathrm{p}=0.26)$ or desaturation index $(\mathrm{r}=-0.13 ; \mathrm{p}=0.21)$ in 104 children with confirmed sleep disordered breathing. However, children with high leukotriene B4 (defined as $>75$ th centile of leukotriene B4 levels in healthy controls) were over three times more likely (adjusted OR 3.19, 95\% CI 1.16-8.74; $\mathrm{p}=0.02$ ) to have tonsillar hypertrophy suggesting a link with upper airway inflammation and some aspects of sleep pathogenesis in children.

\section{Infection and inflammation in CF}

Early diagnosis of pulmonary infection with Pseudomonas aeruginosa is necessary to enable timely eradication therapy. However, this is particularly challenging in those who are unable to expectorate sputum. Specific P. aeruginosa quorum sensing signal molecules have potential as biomarkers to aid diagnosis of infection. In a prospective, multicentre observational study over 3 years, UK researchers found a high sensitivity and specificity of such a molecule (2-heptyl-4-hydroxyquinoline (HHQ)) in plasma (86\% sensitivity and $86 \%$ specificity, respectively) and urine $(79 \%, 71 \%)$ compared with conventional microbiological culture [61]. In a longitudinal analysis of 45 children without $P$. aeruginosa infection at baseline, plasma HHQ levels were significantly associated with subsequent positive culture during the following year. The presence of fungi in the airways of patients with CF is common, but the pathogenic role of most fungi is unclear. The most prevalent species are Aspergillus and Candida. Metagenomic studies have opened a new dimension, and can identify a large population of fungal microbiota in CF, which are usually not seen in cultures. In a Spanish, prospective, observational cohort study, metagenomic investigations revealed $82 \%$ had fungi in contrast to none in culture [62]. In adults, metagenomic screening increased the detection rate of fungi from $30 \%$ in culture to $70 \%$; in most cases the fungi were Candida (38\%) and Aspergillus (11\%). Patients with newly acquired fungal isolates had worse lung function when compared with persistent culture-negative patients, suggesting that newly acquired isolates impact on disease progression. A research group from Qatar reported a high prevalence of Candida dubliniensis (65\%) in the sputum of their CF patients. However, the clinical significance of their observation remains unclear [63]. A retrospective data analysis of the UK registry in 2013 revealed an association of inhaled tobramycin and colistin use with increased risk of both non-Aspergillus and Aspergillus fungal isolation, with odds ratios of 1.33 and 1.40, respectively. In contrast to tobramycin use (with an OR 1.34), there was no statistically significant association between colistin use and Aspergillus isolation [64]. Allergic bronchopulmonary aspergillosis (ABPA) causes a high degree of morbidity due to its symptomatology, and the side-effects of long-term corticosteroid therapy. A research team from Germany presented data on the influence of domestic pets on ABPA acquisition. Pet owners showed a higher occurrence of clinical proven ABPA (23\%) compared with non-pet owners (8\%), which was still highly significant after adjustment for other variables in a multiple logistic regression analysis [65]. The Tel-Aviv CF Centre presented their experience with Nocardia infection among 200 CF patients. Eight (4\%) had at least one sputum sample positive for Nocardia; half of whom had a mild course or no symptoms, however, the other half developed severe lung disease, for which they recommend an early aggressive multidrug therapy [66].

Inflammatory markers are a potentially useful tool for monitoring lung disease in CF, but could only be used routinely if they can be measured noninvasively. Researchers from the Australian AREST-CF study 
group measured metabolites from BAL using mass spectrometry, and found an association between decreased levels of adenosine and its metabolite inosine as well as oxidised glutathione and CF lung disease [67]. These data provide new insights into adenosine signalling pathways involved in airway inflammatory responses, and have identified a number of metabolites associated with early disease that could potentially serve as noninvasive biomarkers and therapeutic targets in early CF. In a study from the Netherlands, CF exacerbations were best predicted by a set of nine volatile organic compounds (VOCs), provided that the time interval between breath sampling and exacerbations was not longer than 7 days [68]. VOCs can also be emitted by P. aeruginosa and Aspergillus fumigatus cultures, and their fingerprints are time dependent and differ between mono-cultures and co-cultures, which complicates the in vivo determination [69]. Nitric oxide plays an important role in the regulation of airway calibre and host defence against certain pathogens. In CF airways, nitric oxide is reduced and may contribute to CF lung disease. The mechanisms resulting in reduced airway nitric oxide formation in CF are not completely understood, but recent studies suggest a direct link between cystic fibrosis transmembrane conductance regulator (CFTR) dysfunction and low nitric oxide production from nitric oxide synthases. Changes in FeNO may serve as a biomarker of restored CFTR function in the CF lower airway during CFTR modulator treatment [70]. The effect of ivacaftor on airway nitric oxide has been assessed for the first time by a Canadian research team. They measured FeNO before and 4 weeks after initiation of ivacaftor therapy [71, 72]. In a total of 15 patients, pulmonary function improved significantly and mean \pm SD FeNO increased from $8.5 \pm 5.0$ to $16.2 \pm 15.5 \mathrm{ppb}$. The effect was more pronounced in paediatric compared with adult patients, but there was no linear correlation between changes in FeNO, pulmonary function or sweat chloride concentration.

A French group presented their research on histidinylated polylysines ( $\mathrm{pLK}$ ) and suggest pLK30-His8 as a promising new alternative anti-inflammatory agent or mucolytic, as it is able to compact DNA and liquefy sputum of CF patients [73]. The Catalonia CF newborn screening programme presented their results on cascade carrier testing of relatives when a positive case was discovered [74]. All parents were identified as heterozygous carriers of the corresponding mutation, with the exception of three parents who had, in addition to the corresponding mutation, another CFTR mutation in trans. These three parents all had pathological sweat tests (chloride $65-75 \mathrm{mmol} \cdot \mathrm{L}^{-1}$ ) and mild symptoms, although they had normal lung function. The authors believe this emphasises the benefits of genetic testing of parents for potential new $\mathrm{CF}$ diagnoses, as well as informing genetic counselling for families. However, there are potential drawbacks such as discovering non-paternity, which is a recognised issue in most countries.

There is ongoing controversy about the routine use of bronchodilators in CF. The effect of long-term anticholinergic tiotropium bromide therapy in patients with CF has never been investigated. In a retrospective study of 172 patients, subjects treated with tiotropium bromide for 24 months showed a significant difference in mean annual change of FEV1 [75]. However, this difference was small $(0.43 \pm 4.4 \%$ versus $-2.2 \pm 5.18 \%$ in controls), and tiotropium bromide therapy was not associated with a lower exacerbation risk. Nevertheless clinical experience shows this can be useful in patients with intractable wheezing not responding to usual combination therapy with inhaled corticosteroids and a long-acting $\beta_{2}$-agonist.

\section{Neonatology and intensive care}

In a very recent Cochrane review, elective use of high frequency oscillatory ventilation (HFOV) was shown to reduce the risk of BPD; however, lung mechanics during HFOV is still incompletely understood [76]. To elucidate this, two studies from the same research group evaluated the use of resonant frequency in infants and demonstrated for the first time that non-uniform chest wall displacement decreased with increasing oscillation frequency, but asynchronies became more evident [77, 78]. In a study by BнAT et al. [79], lung mechanics during volume-targeted ventilation were compared with pressure-limited ventilation in a group of term or near-term infants and found to be associated with fewer episodes of hypocarbia, although not a reduction in the time to successful extubation. This is very similar to what has been previously reported by the same group of researchers regarding preterm infants suggesting that, regardless of gestational age, an important benefit of volume-targeted ventilation is reduction of the risk for over-ventilation [80]. In a very elegant experimental study, Bourke et al. [81] could visualise the response to methacholine in a mouse model of BPD and using phase-contrast microscopy demonstrated an excessive contraction in the small airways of lungs exposed to hyperoxia and perinatal inflammation. The susceptibility to AHR in children with BPD is a clinical problem, with twice as many of former BPD patients being asthmatic at school age [82]. This model holds the potential for further investigations of the underlying mechanisms to reveal new targets for treatment of airway hyperreactivity in BPD.

Newborn infants, and particularly those born preterm, are at risk for apnoea due to immature autoregulation of respiration; however, several factors may play a role and the following studies have contributed to increased knowledge about the mechanisms behind apnoea in the newborn period. Rossor et al. [83] have demonstrated an increased ventilatory response to hypercarbia in preterm infants receiving 
caffeine therapy. Contrary to this, term infants of smoking and substance abusing mothers exhibited a dampened ventilatory response to hypercarbia, possibly contributing to an increased risk for sudden infant death syndrome [84]. Finally, with the use of synchronised PSG and pH intraluminal impedance no causal relationship between gastro-oesophageal reflux and apnoea could be shown in a mixed group of term and preterm infants [85]. Caffeine therapy for apnoea of prematurity has been shown to reduce the rates of cerebral palsy and cognitive delay; however, no long-term effects on survival without disability or sleep apnoea have been found [86].

Evidence is now accumulating regarding the use of high-flow nasal cannula (HFNC) in the newborn period. In a systematic review conducted by CHAKRABORTY et al. [87], data from a total of 1112 preterm infants enrolled in randomised or quasi-randomised clinical trials were analysed showing similar efficacy to other modes of noninvasive ventilation. As previously reported there was a significant reduction in the incidence of nasal trauma with HFNC, but also a trend towards lower rates of air leaks and mortality. A majority of the infants were born moderately to late preterm suggesting that, at least in this group of more mature infants, the safety profile with less adverse effects is an advantage of HFNC. Interestingly, this is in line with the preference of nursing staff according to a recent study in which nurses favoured nasal continuous positive airway pressure (CPAP) as the choice of respiratory support post-extubation in the most preterm infants, but preferred HFNC in infants $>28$ weeks gestation [88].

In very preterm infants, one of the most commonly used indications for HFNC in clinical practice is weaning from CPAP in infants with evolving or established BPD. In a small cross-over study performed around 2 weeks of age in preterm infants with an average gestational age of 27 weeks, SHETTY et al. [89] reported no significant advantage with regard to work of breathing, thoracoabdominal asynchrony or oxygen saturations with HFNC compared with CPAP. Evidence from YoDER et al. [90] suggests that HFNC is comparable to nasal CPAP in preventing extubation failure, but data on various other indications for HFNC use is lacking. HFNC as the primary mode of respiratory support in preterm infants will be tested the HIPSTER study, a randomised trial designed for noninferiority, and others studies are on the way [91].

\section{Infection and immunity}

Respiratory viral infections remain a major cause of morbidity and mortality worldwide. The importance of neutrophils in the inflammatory response to respiratory viruses is now well known. While their role in contributing to the severity of symptoms appears well established it is still unclear how important they are in viral clearance. SAINT et al. [92] presented data from in vitro gene microarray experiments suggesting that when neutrophils are exposed to the respiratory syncytial virus (RSV) a number of antiviral pathways are activated. They concluded that this supported the suggestion that neutrophils play an important active role in the innate antiviral response. FonsECA et al. [93] presented data from a rodent model of RSV infection in which, as expected, the acute illness was characterised by an intense airways neutrophilia that rapidly resolved. However, following these animals to 21 days post-infection there was persistence of viral replication in airways dendritic cells although no virus was identifiable in BAL, suggesting that the virus may be able to persist at low levels in these cells in vivo as well as in vitro. The same group also presented evidence to support the suggestion that the virus may be acquired in utero [94]. Their study found evidence of viral RNA in $60 \%$ of human cord blood monocytes and they speculated that in utero exposure may have an impact on the host's ability to mount an effective long-term memory response. Admissions to hospital with acute bronchiolitis continue to place a considerable burden on health systems. Boyd et al. [95] undertook a health economics assessment of changing the criteria for taking infants out of oxygen using a threshold saturation of $90 \%$ in air rather than $94 \%$ and suggested that this would result in a saving of approximately EUR 356 per patient without any compromise in safety. This does of course only apply to infants whose saturation in air falls below $94 \%$ so cannot be extrapolated to all admissions, and it is also important to remember this was undertaken in patients in whom the saturation data was being used to inform when oxygen therapy should be discontinued, that is they were in the recovery phase of the illness. Hence the results should not be extrapolated to the concept that any infant with saturations $>90 \%$ early in the course of the illness can be safely discharged. A Russian group presented data suggesting that the use of recombinant $\alpha 2$-interferon administered once daily to children aged $<3$ years admitted with respiratory viral infections resulted in more rapid resolution of inflammation and clearance of virus [96].

Prevention remains the goal of much of this research, but to date, there is no imminent prospect of an effective vaccine entering routine practice. A large Canadian study retrospectively reviewed outcomes for more than 19000 infants who had been prescribed palivizumab for any reason enrolled over a 9-year period. They found that, when compared with the $60 \%$ who received all five doses, health outcomes in those who were less compliant were worse [97]. The increase in hospitalisation was relatively modest, but duration of hospitalisation if admitted was markedly increased (7.8 versus 16.6 days). Effectively addressing the issues underlying low rates of compliance remains one of the great challenges across the whole of healthcare. A second large study from 
the same group found no significant benefit could be identified among infants with CF given palivizumab when compared with infants with CF who did not receive the humanised antibodies [98].

The study by KORTEN et al. [99] addressing the impact of rhinovirus infections on the nasopharyngeal microbiota exemplified the potential of modern sequencing techniques to transform our understanding of the interactions between the human host and microbiota occupying different niches within and on the body, and how these interactions drive important components of health and disease. By sampling the nasopharynx biweekly they confirmed that many rhinovirus infections were largely asymptomatic. Their data indicates that symptomatic infections appear to be associated with lower bacterial diversity and higher bacterial density, in large part supporting some earlier studies using conventional microbiology indicating that density of bacterial pathogens is an important determinant of the severity of nasal symptoms in those with an apparent viral "cold". As in other studies, they found a degree of resilience within the microbiome although the change might persist for up to 3 weeks. Frequent symptomatic infections did appear able to produce more long lasting changes.

Studies addressing the potential for host factors to impact on these interactions included studies addressing the structure and function of cilia. HiRst et al. [100] demonstrated electron microscopy changes in some cilia from some patients with conditions included under the umbrella term ciliopathies (genetic disorders of non-motile cilia) (figure 1). A multinational team used immunofluorescence to explore functional correlates of genetic mutations in patients with PCD and proposed this approach would be valuable in diagnosis of patients with loss-of-function mutations and missense variants [101]. Another condition associated with significant respiratory morbidity is ataxia telangiectasia. DevANEY et al. [102] highlighted the delay in diagnosis of ataxia telangiectasia, although they were unable to identify an impact of this delay on respiratory status. The potential of targeting host mediators in order to prevent disease progression was again raised in a presentation in which the authors noted that ceramides detected in tracheal aspirates from premature infants varied between those who developed chronic lung disease and those who did not [103] A group from London presented data suggesting that aspiration was relatively common in apparently normal children with chronic or recurrent respiratory problems [104]. Interestingly, there was apparently no difference in the pattern of symptoms or severity in those in whom aspiration was judged to occur as compared with those in whom it was considered that aspiration was not occurring.

FIGURE 1 Cystic cilia tip from Sensenbrenners ciliopathy. Reproduced from [100] with permission from the author.

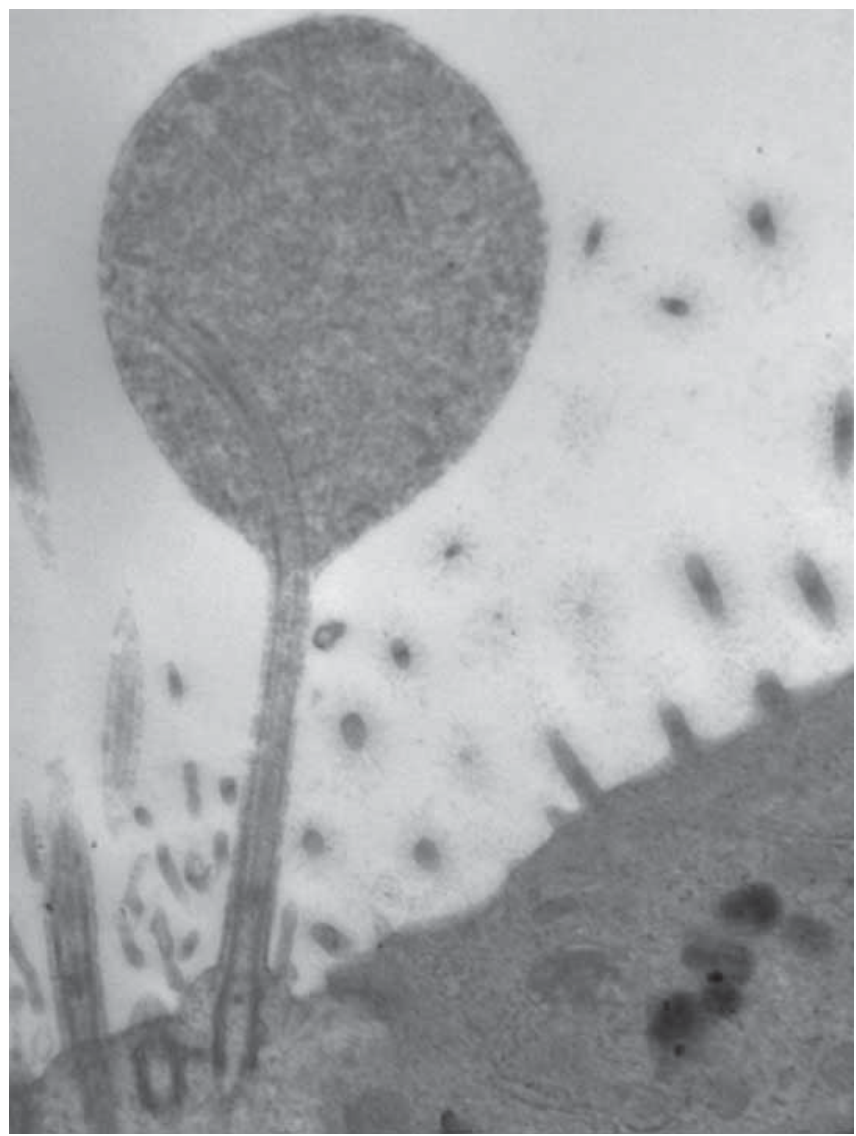


Other groups addressed a range of infectious diseases. A group from Korea again highlighted the importance of considering Chlamydia trachomatis as a cause of acute respiratory illness in infancy, with the organism being identified in $8.3 \%$ of a very large cohort of infants with acute bronchiolitis [105]. The potential use of novel technologies in directing management was raised by an exploratory study in which MALDI-TOF mass spectrometry was used to characterise protein composition associated with parapneumonic effusions [106]. The challenges of early diagnosis and instituting appropriate therapy for hydatid disease even in areas in which it is endemic was again raised, with the authors noting that $18 \%$ of subjects required lobectomy [107]. Research into pulmonary infections and host responses is entering an exciting period as the power of "omics" technologies such as gene sequencing (16S rRNA and the more complex "shotgun" sequencing) metabolomics and computational biology are brought into this area.

\section{Viruses and asthma and the airway microbiome}

The role of viruses in asthma pathogenesis and asthma symptoms remains a hot topic. In a symposium on virus-driven and host-defence immune responses in acute virus-induced asthma James Gern (University of Wisconsin, Madison, WI, USA) argued that allergic inflammation inhibits interferon responses to virus infections, with rhinovirus $\mathrm{C}$ being the most prominent example. This was in line with a recent review by LAMBRECHT et al. [108] on the immunology of asthma. In this review, reduced interferon production after exposure to viral agents, due to interference with eosinophil-derived transforming growth factor- $\beta$ and upregulation of chitinases and chitinase-like proteins, was suggested to be related to increased susceptibility to viruses in patients with asthma. According to James Gern, this decreased response may be attenuated by omalizumab. He showed data that omalizumab reduces rhinovirus-induced asthma attacks during the peak season and speculated that enhanced interferon- $\alpha$ production by omalizumab reduces viral replication, thereby mitigating disease severity and exacerbation risk [109]. Whether inhaled interferons may reduce or mitigate viral exacerbations in asthma remains to be seen.

Peter Le Soeuf (The University of Western Australia, Crawley, Australia) showed that viral infections are associated with an altered airway microbiome, which may lead to a higher risk of viral infection and asthma. Michael Cox (Imperial College, London, UK) showed that the airway microbiome is an equilibrium that can be influenced by internal and external factors. Diseases may cause selection of the microbiome and asthma severity seems to be associated with changes in the microbiome. However, in a small number of infants diagnosed with wheeze, no significant differences were found in the airway microbiome between acute attacks and during short-term follow-up. However, rhinovirus infections did change the bacterial copy numbers in patients with chronic obstructive pulmonary disease and, not surprisingly, smoking alters the airway microbiome. Studies on the influence of the airway microbiome on asthma development are scarce. A small study in children suggested that microbiome characteristics modulate host inflammatory and immune systems in patients with asthma [110]. TeO et al. [111] studied the nasopharyngeal microbiome during the first year of life in 234 infants and looked at both viral and bacterial communities. Early asymptomatic colonisation with Streptococcus strongly predicted asthma, and not surprisingly antibiotics disrupted the microbiome. The authors suggest that the nasopharyngeal microbiome might offer preventive strategies to asthma development by targeting pathogenic bacteria. Whether manipulation of the airway microbiome may offer new opportunities to interfere with airways and lung diseases remains to be shown, but is a highly exciting area.

\section{E-health in paediatric asthma}

Two multicentre studies from the Netherlands assessed the effect of a text alert to improve adherence to inhaled medication and of a virtual asthma clinic, respectively $[112,113]$. With real-time medication monitoring coupled with text reminders VASBINDER et al. [112] were able to improve adherence to treatment; however, this did not result in better asthma control or asthma-related quality of life. Results were similar in the UK, where an intervention using electronic monitoring with feedback (figure 2) did not improve asthma control as assessed by the primary outcome, the Asthma Control Questionnaire (figures 3 and 4), although secondary outcomes such as hospital admissions and oral steroid courses were reduced in the feedback group [114]. Technical problems such as broken or lost devices were frequent in the intervention group. Jochmann et al. [115] from London used Smartinhalers (Adherium Ltd, Auckland, New Zealand) to assess adherence and showed that, despite the patients being aware that adherence was monitored, 58\% of the children used $<80 \%$ of prescribed medication. Self-reported adherence (Medicine Adherence Rating Scale questionnaire) did not reflect this and prescription uptake only weakly reflected electronically monitored adherence. Asthma control measures improved in the children with moderate-to-good adherence to treatment. The second Dutch study showed that replacing clinic visits with web-based contacts was successful in the so-called virtual asthma clinic used by VAN DEN WIJNGAART et al. [113]. While reducing clinic visits by $50 \%$ similar asthma control could be maintained by offering patients and their parents web-based contacts. VoOREND-VAN BERGen et al. [116] showed that a somewhat similar approach was cost-effective. Fortunately adolescents and parents have a positive attitude to having their adherence 
FIGURE 2 Electronic adherence monitor (Smartinhaler; Adherium, Auckland, New Zealand). Image courtesy of Mark L. Everard.

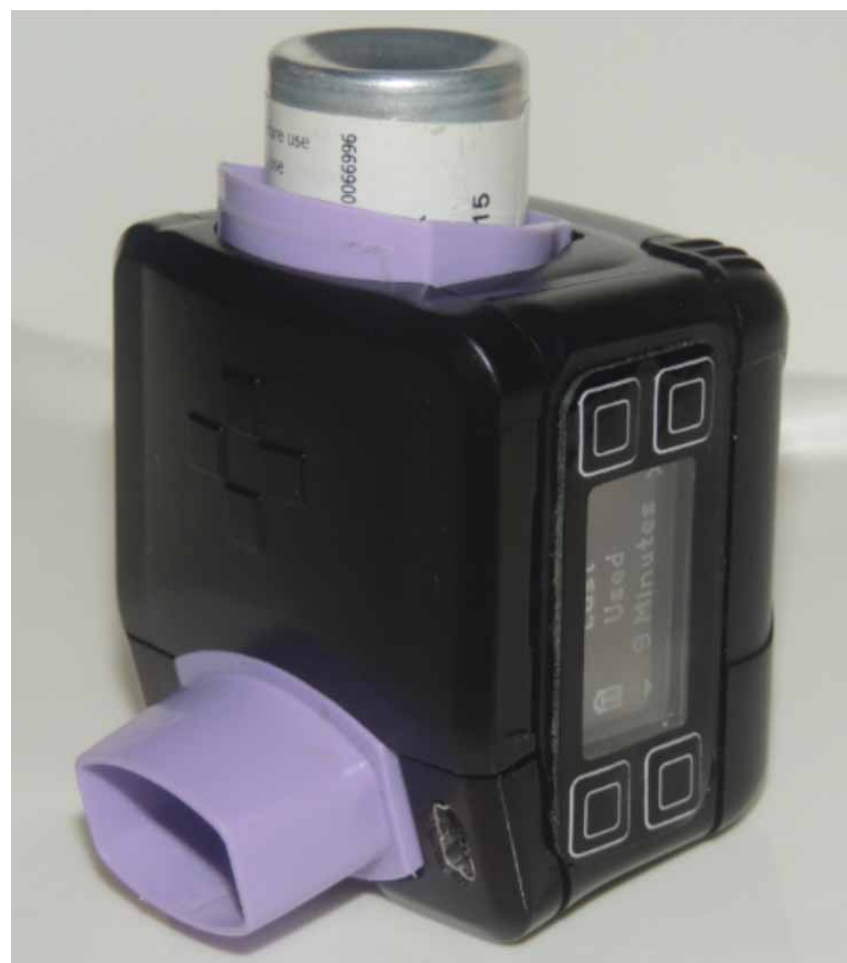

measured and shared with healthcare providers, although the social acceptability of Smartinhalers needs attention [117]. Although systematic reviews did not show an overall effect of e-health interventions on asthma outcomes, careful analyses of studies that did show an effect can be helpful in determining which interventions may be useful, in which populations, how often and how extensively [118].

\section{Visualising the airway and lung}

ANTÓN-PACHECO et al. [119] presented the long-term outcome and the quality of life of a group of children with severe airway malacia who had undergone metallic stenting. Seven out of 23 patients had their stents in place for more than 5 years. 13 metallic stents, one tracheal and 12 bronchial, were bronchoscopically placed at median age of 5 months. Complications were fewer than expected. The impact on the quality of life was considered as mild to moderate. KRIVEC et al. [120] also presented their experience with therapeutic interventions in the airways during flexible bronchoscopy. In 37 patients (median age 2.8 years, range $0.1-17.0$ years) they performed 55 procedures, including large mucous plugs and bronchial cast removals (39 procedures), foreign body extractions (nine procedures) and other airway occlusion resolutions (one large laryngeal granulation, two subglottic membranes, one tracheal membrane and three bronchial membranes). No serious complications were reported.

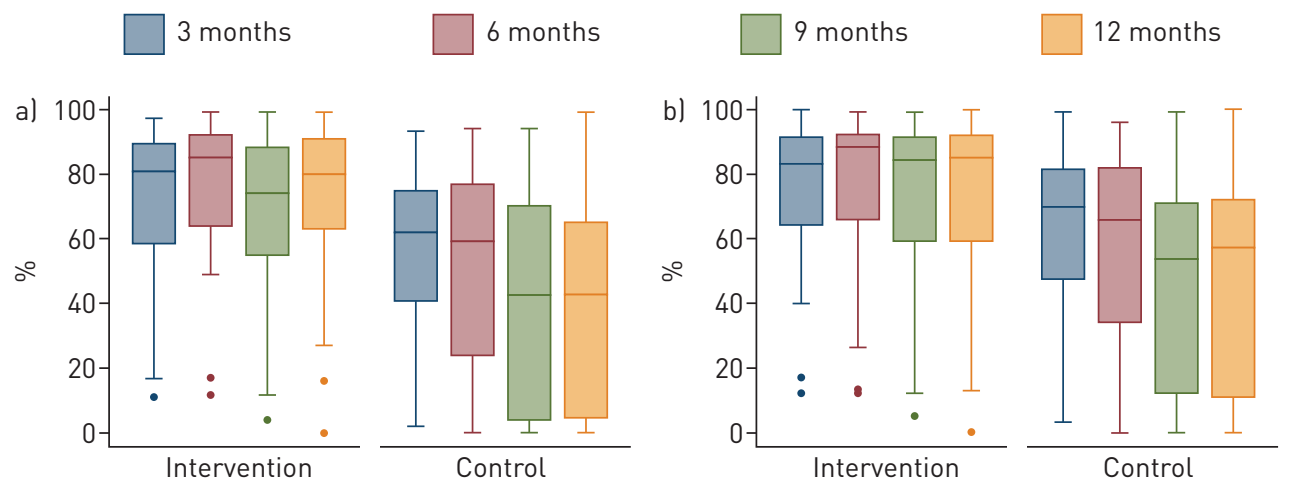

FIGURE 3 Adherence over a year for the intervention (Smartinhaler feedback group; adherence $=70 \%$ for the whole 12 months) and control (normal care; adherence=49\% for the whole 12 months) groups in a) the morning and b) the afternoon. The boxes represent the interquartile range and the horizontal lines indicate the median. Data from [114] with permission from the author. 
FIGURE 4 Asthma Control Questionnaire (ACQ) scores for the intervention and control groups. Data from [114] with permission from the author.

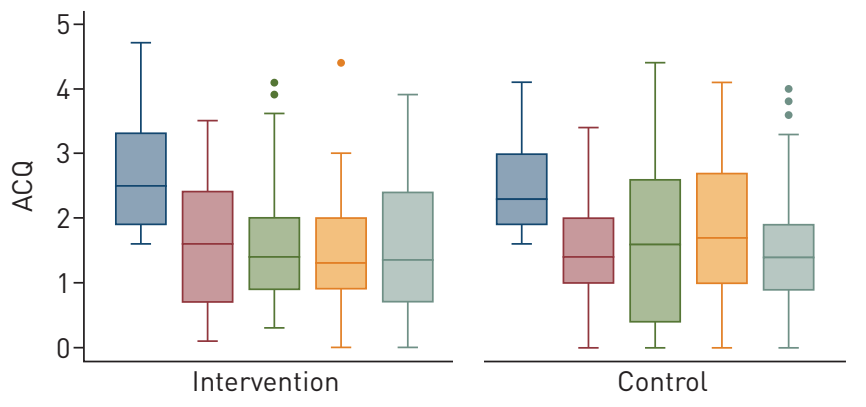

In tracheomalacia, Douros et al. [121] studied the use of helical CT scans in 21 children with brassy cough or, as they call it, "vibrating" cough (accompanied by a sense of vibration in the chest wall). All children underwent fibre-optic bronchoscopy and tracheomalacia was confirmed in 19 children, who were further investigated with helical CT. The cross-sectional area ratio of the trachea at the level of maximum end-expiration collapse during end-expiration and end-inspiration (CSR), determined the basis for the helical CT diagnosis. Four children who underwent helical CT scans for reasons unrelated to tracheomalacia served as controls. Mean (95\% CI) CSR was 0.59 (0.54-0.65) and $0.89(0.78-0.98)$ in patients and controls, respectively. Helical CT diagnosed tracheomalacia in four (21\%), $13(68 \%)$ and $17(89 \%)$ patients, if the criterion used was CSR $\leqslant 0.5$, CSR $\leqslant 0.6$ and CSR $\leqslant 0.7$, respectively. All the controls had CRS $>0.7$. The authors proposed that CSR $\leqslant 0.7$ would be an appropriate threshold for tracheomalacia in children.

In a retrospective study, FASSEEH et al. [122] reviewed 97 infants (78.4\% females) who were diagnosed with subglottic haemangioma at Alexandria University Hospitals in Egypt from 2002 to 2012. The mean age of onset and diagnosis were $2.8 \pm 1.1$ and $5.6 \pm 1.7$ months, respectively. It was noted that $87.6 \%$ of the cases had biphasic stridor, $68 \%$ had grade 3 airway obstruction and $35.1 \%$ were associated with cutaneous haemangiomas. Most of the cases received oral propranolol (52.6\%), some received systemic steroids (30.9\%) and a few received both oral steroids and propranolol (16.5\%). In the steroids group, $40 \%$ of the cases showed a rapid response, $36.7 \%$ showed a slow response and $23.3 \%$ of cases did not respond to treatment. The best response rate was noted in the propranolol group (98.0\%) with a rapid or even very rapid response to treatment without reported side-effects. In an interesting Spanish multicentre retrospective study (involving 11 centres), MoRENo et al. [123] presented data regarding the anatomical and clinical characteristics of tracheal bronchus. 93 patients with tracheal bronchus diagnosed by bronchoscopy $(81.6 \%)$ and/or chest CT were included. All of them were right sided and $66 \%$ were in the lower third of the trachea. Broncho-obstructive episodes (60.2\%) were the predominant clinical manifestation reported, whereas $44 \%$ had pneumonia. Children with tracheal bronchus were associated with heart disease (39.7\%), tracheomalacia (35.5\%), gastro-oesophageal reflux (31\%) and Down syndrome (10.5\%). Most of them (73\%) had a favourable outcome.

WALKER et al. [124] investigated whether physician's interpretation of gross findings in children with persistent respiratory symptoms correlated with the information obtained during bronchoscopies they underwent regarding the appropriate antibiotic prescription. They retrospectively audited the bronchoscopic findings, BAL cell count and culture, and decision to commence antibiotics over a 3-month period in one paediatric centre. 22 patients aged 1-15 years underwent bronchoscopy and BAL. The commonest indication was persistent cough. These results gave a sensitivity of $84 \%$ and specificity of $57 \%$ for the physician decision to initiate antibiotics based on macroscopic bronchoscopy findings. The authors concluded that experienced physician decisions to initiate antibiotics based on bronchoscopy findings have good sensitivity and result in the majority of patients receiving antibiotics appropriately.

Exercise-induced asthma is considered the most common cause of exertional dyspnoea, but other causes such as cardiovascular or pulmonary diseases, poor fitness, hyperventilation and vocal cord dysfunction are also implicated. However, a significant proportion of symptomatic adolescents do not fit into these categories with symptoms of dysfunctional breathing limiting physical activity. BeNzrath et al. [125] presented data on 59 adolescents with exercise-induced dysfunctional breathing other than exercise-induced asthma. 45 patients showed dysfunctional breathing, but did not meet the criteria of hyperventilation or vocal cord dysfunction. They were considered to have exercise-induced dyspnoea. Frequently there was a history of competitive sport. Typically dyspnoea was accompanied by significant lactic acidosis and oxygen desaturation, as in exercise-induced arterial hypoxaemia. Patients showed a typical breathing pattern, and usually showed a good response to physiotherapy aiming at modification of the breathing pattern. 
The clinical utility of routine CT chest scanning is still debated, as CT scanning in young children often requires sedation and the biological effects of radiation later in life are uncertain. Some still advocate for routine annual surveillance, while most believe it should be restricted to clinical need on an individual basis. Due to technical progress, the scanning time can be reduced to $0.4 \mathrm{~s}$ and radiation exposure can be reduced further. This makes CT scanning possible during normal breathing (CT-b) without anaesthesia, and has been investigated in infants with and without CF in the first year of life. All CT-b scans showed good concordance between the two scores for air trapping (intraclass correlation coefficient $=0.98$ ). Infants with CF showed a significant increase in air trapping score expressed as a z-score at 10 weeks and 1 year of age [126]. Due to concerns over the radiation burden of CT scans, there is still an interest in the use of magnetic resonance imaging (MRI) for long term monitoring of lung disease. Researchers from Heidelberg investigated the correlation between MBW and MRI chest scores in children with CF and healthy subjects. Morphological, perfusion and global MRI chest scores were elevated in stable CF children and were positively correlated with a higher LCI z-score; the concordance between abnormal findings in MBW and MRI was above 70\% [127]. Both had worsening scores during an exacerbation, and significantly improved after antibiotic therapy. However, use of MRI scanning in routine clinical practice seems unlikely given the time, expense and the fact that sedation or general anaesthesia are required for younger patients.

\section{References}

1 Zugna D, Galassi C, Annesi-Maesano I, et al. Maternal complications in pregnancy and wheezing in early childhood: a pooled analysis of 14 birth cohorts. Int J Epidemiol 2015; 44: 199-208.

2 Lodge C, Lowe A, Dharmage S, et al. Does grandmaternal smoking increase the risk of asthma in grandchildren? Eur Respir J 2015; 46: Suppl. 59, OA4762.

3 Pesce G, Marcon A, Marchetti P, et al. Fetal exposure to pregnancy complications and respiratory health in childhood: a longitudinal study. Eur Respir J 2015; 46: Suppl. 59, OA4765.

4 Cheelo M, Lodge CJ, Dharmage SC, et al. Paracetamol exposure in pregnancy and early childhood and development of childhood asthma: a systematic review and meta-analysis. Arch Dis Child 2015; 100: 81-89.

5 Migliore E, Zugna D, Galassi C, et al. Prenatal paracetamol exposure and wheezing in childhood: causation or confounding? PLoS One 2015; 10: e0135775.

6 Magnus MC, Karlstad Ø, Håberg SE, et al. Prenatal and infant paracetamol exposure and development of asthma. Eur Respir J 2015; 46: Suppl. 59, OA4766.

7 Loss G, Apprich S, Waser M, et al. The protective effect of farm milk consumption on childhood asthma and atopy: the GABRIELA study. J Allergy Clin Immunol 2011; 128: 766-773.

8 Brick T, Schober Y, Böcking C, et al. Content of omega-3 fatty acids partially explains the asthma-protective effect of unprocessed cow's milk. Eur Respir J 2015; 46: Suppl. 59, OA4768.

9 Popovic M, Pizzi C, Rusconi F, et al. Infant weight trajectories and early childhood wheezing: the NINFEA birth cohort study. Eur Respir J 2015; 46: Suppl. 59, OA4767.

10 Smit LA, Bouzigon E, Pin I, et al. 17q21 variants modify the association between early respiratory infections and asthma. Eur Respir J 2010; 36: 57-64.

11 Loss G, Depner M, Roduit C, et al. Chr17q21 modifies environmental effects on respiratory infections in infancy and effects on asthma. Eur Respir J 2015; 46: Suppl. 59, OA3481.

12 Holloway JW, Savarimuthu Francis S, Fong KM, et al. Genomics and the respiratory effects of air pollution exposure. Respirology 2012; 17: 590-600.

13 Bowatte G, Lodge C, Erbas B, et al. The influence of traffic-related air pollution (TRAP) on asthma and allergies modified by polymorphisms in GSTT1, GSTM1, GSTP1 and GSTCD. Eur Respir J 2015; 46: Suppl. 59, OA1470.

14 Lau M, Dharmage S, Win A, et al. Exposure to siblings in early life modifies the association between CD14 polymorphisms and allergic sensitization in adult life. Eur Respir J 2015; 46: Suppl. 59, OA1471.

15 Barbato A, Frischer T, Kuehni CE, et al. Primary ciliary dyskinesia: a consensus statement on diagnostic and treatment approaches in children. Eur Respir J 2009; 34: 1264-1276.

16 Panajotis K, Papatheodorou S, Yiallouros P. Diagnostic accuracy of nasal nitric oxide measurement for establishing diagnosis of primary ciliary dyskinesia: a systematic review and meta-analysis. Eur Respir J 2015; 46: Suppl. 59, PA4516.

17 Collins S, Behan L, Evans H, et al. The accuracy of nasal nitric oxide testing in PCD diagnostics is population specific. Eur Respir J 2015; 46: Suppl. 59, PA4517.

18 Halbeisen FS, Goutaki M, Maurer E, et al. Lung function in patients with primary ciliary dyskinesia (PCD): a multinational study. Eur Respir J 2015; 46: Suppl. 59, OA3480.

19 Goss CH, MacNeill SJ, Quinton HB, et al. Children and young adults with CF in the USA have better lung function compared with the UK. Thorax 2015; 70: 229-236.

20 The joint American Thoracic Society/European Respiratory Society working group on infant lung function. The raised volume rapid thoracoabdominal compression technique. Am J Respir Crit Care Med 2000; 161: 1760-1762.

21 Frey U. Clinical applications of infant lung function testing: does it contribute to clinical decision making? Paediatr Respir Rev 2001; 2: 126-130.

22 Peterson-Carmichael SL, Rosenfeld M, Ascher SB, et al. Survey of clinical infant lung function testing practices. Pediatr Pulmonol 2014; 49: 126-131.

23 Lum S, Bountziouka V, Wade A, et al. Equipment specific reference ranges for the raised volume technique (RVRTC) in infants: a multi-centre collaboration. Eur Respir J 2015; 46: Suppl. 59, PA1261.

24 Jones $\mathrm{M}$, Castile R, Davis $\mathrm{S}$, et al. Forced expiratory flows and volumes in infants. Normative data and lung growth. Am J Respir Crit Care Med 2000; 161: 353-359.

25 Sherrill DL, Guerra S, Wright AL, et al. Relation of early childhood growth and wheezing phenotypes to adult lung function. Pediatr Pulmonol 2011; 46: 956-963. 
Turner SW, Young S, Goldblatt J, et al. Childhood asthma and increased airway responsiveness: a relationship that begins in infancy. Am J Respir Crit Care Med 2009; 179: 98-104.

27 Kowalik K, Lu Z, Lou W, et al. Feasibility of performing pulmonary function testing in cohort studies. Eur Respir J 2015; 46: Suppl. 59, PA1270.

28 Gray D, Willemse L, Visagie A, et al. Longitudinal infant lung function measures in unsedated infants. Eur Respir J 2015; 46: Suppl. 59, OA3500.

29 Pfleger A, Steinbacher M, Schwantzer G, et al. Spirometry and multiple breath nitrogen washout (MBNW) before and after cold dry air challenge (CACh) in children and adolescents with asthma. Eur Respir J 2015; 46: Suppl. 59, P3639.

30 De Leeuw R, Irving S, Saglani S. Addressing current gaps in the clinical utility of lung clearance index (LCI) in school aged children with asthma. Eur Respir J 2015; 46: Suppl. 59, PA3640.

31 Ghezzi M, Tenero L, Piazza M, et al. Structured light plethysmography: new method to evaluate expiratory flow limitation in asthmatic children. Eur Respir J 2015; 46: Suppl. 59, P3641.

32 Hmeidi H, Chadwick E, Lenney W, et al. Changes in respiratory function following bronchodilator in acute paediatric asthma measured using structured light plethysmography. Eur Respir J 2015; 46: Suppl. 59, P3642.

33 Hmeidi H, Chadwick E, Lenney W, et al. Non-invasive, non-contact measurement of tidal breathing parameters in children aged 3-17 years using structured light plethysmography (SLP). Eur Respir J 2015; 46: Suppl. 59 , P3643.

34 Hall GL, Irvin CG. Using lung function measurements to greater advantage in patients with lung disease: which test and when? Respirology 2014; 19: 780-781.

35 Nyilas S, Yammine S, Kumar N, et al. Different indices of inert gas washout measurements define physiological phenotypes. Eur Respir J 2015; 46: Suppl. 59, PA1264.

36 Salzmann S, Yammine S, Krüger L, et al. Ability of lung clearance index to track changes in a routine clinical CF setting. Eur Respir J 2015; 46: Suppl. 59, PA1265.

37 Hatziagorou E, Avramidou V, Kampouras A, et al. Lung clearance index changes over time among patients with cystic fibrosis. Eur Respir J 2015; 46: Suppl. 59, OA3502.

38 Jayasuriya G, King G, Selvadurai H, et al. Peripheral airway abnormalities are common in children post bone marrow transplantation. Eur Respir J 2015; 46: Suppl. 59, PA1269.

39 Bar-Yishay E, Matyashchuk E, Prais D, et al. Lung function in school age children with chronic lung disease of prematurity. Eur Respir J 2015; 46: Suppl. 59, OA3505.

40 Simpson SJ, Hall GL, Wilson AC. Lung function following very preterm birth in the era of 'new' bronchopulmonary dysplasia. Respirology 2015; 20: 535-540.

41 O'Dea C, Logie K, Wilson A, et al. Structural abnormalities do not explain the reduced exercise capacity in preterm children. Eur Respir J 2015; 46: Suppl. 59, PA1256.

42 Simpson S, Logie K, Verheggan M, et al. Longitudinal lung function in school-age children born very preterm. Eur Respir J 2015; 46: Suppl. 59, OA3505.

43 Subbarao P, Stanojevic S, Brown M, et al. Lung clearance index as an outcome measure for clinical trials in young children with cystic fibrosis. A pilot study using inhaled hypertonic saline. Am J Respir Crit Care Med 2013; 188: 456-460.

44 Ramsey KA, Rosenow T, Turkovic L, et al. Lung clearance index and structural lung disease on computed tomography in early cystic fibrosis. Am J Respir Crit Care Med 2016; 193: 60-67.

45 Vermeulen F, Proesmans M, Boon M, et al. Lung clearance index predicts pulmonary exacerbations in young patients with cystic fibrosis. Thorax 2014; 69: 39-45.

46 Sonneveld N, Stanojevic S, Amin R, et al. Lung clearance index in cystic fibrosis subjects treated for pulmonary exacerbations. Eur Respir J 2015; 46: 1055-1064.

47 Sonneveld N, Stanojevic S, Jensen R, et al. Does the lung clearance index track with disease progression in early childhood? Eur Respir J 2015; 46: Suppl. 59, PA2049.

48 Ramsey K, Ranganathan S, Grdosic J, et al. Ability of the lung clearance index to detect inflammation and infection in preschool children with cystic fibrosis. Eur Respir J 2015; 46: Suppl. 59, PA2052.

49 Duncan J, Raywood E, Wade A, et al. Preschool lung clearance index (LCI) predicts adolescent lung function in cystic fibrosis (CF). Eur Respir J 2015; 46: Suppl. 59, PA2050.

50 Hatziagorou E, Kampouras A, Avramidou V, et al. Exercise testing and multiple breath washout as markers of lung disease among patients with cystic fibrosis. Eur Respir J 2015; 46: Suppl. 59, PA2048.

51 Kavouridou C, Gustafsson P, Rosberg M, et al. Comparing two different algorithms of calculating LCI and FRC from $\mathrm{N}_{2}$ MBW in children with CF. Eur Respir J 2015; 46: Suppl. 59, PA2051.

52 Anagnostopoulou P, Yammine S, Schmidt A, et al. False normal lung clearance index in infants with cystic fibrosis due to software algorithms. Pediatr Pulmonol 2015; 50: 970-977.

53 Ayas NT, Owens RL, Kheirandish-Gozal L. Update in sleep medicine 2014. Am J Respir Crit Care Med 2015; 192: 415-420.

54 Trosman I. Childhood obstructive sleep apnea syndrome: a review of the 2012 American Academy of Pediatrics guidelines. Pediatr Ann 2013; 42: 195-199.

55 Sivan Y, Domany KA, Gut G, et al. Comparison between adenotonsillectomy and adenoidectomy in the treatment of obstructive sleep apnea in children. Eur Respir J 2015; 46: Suppl. 59, OA1477.

56 van Eyck A, Vanheeswijck L, Lambrechts C, et al. The role of nocturnal pulse oximetry in the screening for obstructive sleep apnea in obese children and adolescents. Eur Respir J 2015; 46: Suppl. 59, OA1481.

57 Weber SA, Barros J, Marão AC, et al. Unattended sleep studies in children: is it worth? Eur Respir J 2015; 46: Suppl. 59, OA1482.

58 Goldbart AD, Tal A. Inflammation and sleep disordered breathing in children: a state-of-the-art review. Pediatr Pulmonol 2008; 43: 1151-1160.

59 Supino MC, Bonafoni S, Evangelisti M, et al. Oxidative stress in children with OSAS: 8-isoprostane values comparison in urine and exhaled breath condensate (EBC). Eur Respir J 2015; 46: Suppl. 59, PA2421.

60 Alexopoulos E, Haritos G, Befani C, et al. Serum leukotriene $\mathrm{B}_{4}$ levels, tonsillar hypertrophy and obstructive sleep-disordered breathing in childhood. Eur Respir J 2015; 46: Suppl. 59, PA4169.

61 Barr H, Halliday N, Camara M, et al. Systemic quorum sensing signal molecules are biomarkers for current and future P. aeruginosa infection in cystic fibrosis patients: a longitudinal study. Eur Respir J 2015; 46: Suppl. 59, OA1438. 
Carrasco Hernández L, López Ramírez C, Quintana Gallego E, et al. Temporal progression of fungal microbiota in patients with cystic fibrosis. Eur Respir J 2015; 46: Suppl. 59, OA1440.

Abdul Wahab A, Salah H, Kolecka A, et al. Persistence of Candida dubliniensis in the lower airways of cystic fibrosis patients. Eur Respir J 2015; 46: Suppl. 59, PA2058.

Lugg R, Daniels T. Is there a relationship between use of inhaled antibiotics and prevalence of fungal isolates in the respiratory secretions of people with cystic fibrosis? A retrospective data analysis. Eur Respir J 2015; 46: Suppl. 59, OA1441.

Thronicke A, Brandt C, Schwarz C. A new risk factor predicts ABPA in patients with cystic fibrosis. Eur Respir 2015; 46: Suppl. 59, OA1442

Livnat G, Mei-Zahav M, Bentur L, et al. The spectrum of Nocardia lung disease in cystic fibrosis. Eur Respir J 2015; 46: Suppl. 59, PA2059.

Turkovic L, Esther C, Rosenow T, et al. Association between lobe specific bronchoalveolar lavage fluid metabolites and structural lung disease in young children with cystic fibrosis. Eur Respir J 2015; 46: Suppl. 59, PA2055.

Van Horck M, Dompeling E, Jobsis R. Prediction of CF exacerbations in children by exhaled inflammation markers. Eur Respir J 2015; 46: Suppl. 59, PA2056.

Neerincx AH, Geurts B, Jansen JJ, et al. Volatile organic compounds emitted by Pseudomonas aeruginosa and Aspergillus fumigatus mono-cultures and in co-culture. Eur Respir J 2015; 46: Suppl. 59, PA2057.

Kotha K, Szczesniak RD, Naren AP, et al. Concentration of fractional excretion of nitric oxide (FeNO) A potential airway biomarker of restored CFTR function. J Cyst Fibros 2015; 14: 733-740.

Grasemann $\mathrm{H}$, Gonska T, Avolio J, et al. Airway nitric oxide production in patients with cystic fibrosis increases with ivacaftor therapy. Eur Respir J 2015; 46: Suppl. 59, OA1444.

Grasemann $\mathrm{H}$, Gonska T, Avolio J, et al. Effect of ivacaftor therapy on exhaled nitric oxide in patients with cystic fibrosis. J Cyst Fibros 2015; 14: 727-732.

Epinette C, Henry C, Morello E, et al. Histidinylated polylysines: an alternative antibacterial and fluidifying agent in cystic fibrosis. Eur Respir J 2015; 46: Suppl. 59, PA2060.

Gartner S, Alvarez A, Rovira S, et al. Cystic fibrosis diagnosis in adulthood as a result of study of relatives within the newborn screening programme. Eur Respir J 2015; 46: Suppl. 59, OA1443.

Thronicke A, Brandt C, Schwarz C. Long-term tiotropium bromide therapy was retrospectively analyzed in adults with cystic fibrosis. Eur Respir J 2015; 46: Suppl. 59, OA1445.

Cools F, Offringa M, Askie LM. Elective high frequency oscillatory ventilation versus conventional ventilation for acute pulmonary dysfunction in preterm infants. Cochrane Database Syst Rev 2015; 3: CD000104.

Perego M, Zannin E, Marconi L, et al. Regional distribution of chest wall displacements in infants during high frequency oscillatory ventilation (HFOV). Eur Respir J 2015; 46: Suppl. 59, PA1856.

Marconi L, Dognini G, Perego M, et al. Resonance frequency of the respiratory system in premature infants receiving high frequency oscillatory ventilation (HFOV). Eur Respir J 2015; 46: Suppl. 59, PA1857.

Bhat $\mathrm{P}$, Chowdhury $\mathrm{O}$, Shetty $\mathrm{S}$, et al. Volume targeted versus pressure limited ventilation in term born infants. Eur Respir J 2015; 46: PA1863.

Chowdhury O, Patel DS, Hannam S, et al. Randomised trial of volume-targeted ventilation versus pressure-limited ventilation in acute respiratory failure in prematurely born infants. Neonatology 2013; 104: 290-294.

Bourke J, Lam M, Royce S, et al. Small airway hyperresponsiveness is associated with impaired alveolar development in a mouse model of bronchopulmonary dysplasia. Eur Respir J 2015; 46: Suppl. 59, PA1858.

Fawke J, Lum S, Kirkby J, et al. Lung function and respiratory symptoms at 11 years in children born extremely preterm: the EPIcure study. Am J Respir Crit Care Med 2010; 182: 237-245.

Rossor T, Rafferty G, Greenough A. Carbon dioxide sensitivity and caffeine therapy in the prematurely born infant. Eur Respir J 2015; 46: Suppl. 59, PA1860.

Ali K, Rossor T, Bhat R, et al. Ventilatory responses to hypercarbia in infants of smoking and substance abusing mothers at the high risk age for sudden infant death syndrome. Eur Respir J 2015; 46: Suppl. 59, PA1862.

Rossor T, Lingam I, Bhat R, et al. Acid and non acid gastro-oesophageal reflux and apnoea in infants. Eur Respir J 2015; 46: Suppl. 59, PA1865.

Marcus CL, Meltzer LJ, Roberts RS, et al. Long-term effects of caffeine therapy for apnea of prematurity on sleep at school age. Am J Respir Crit Care Med 2014; 190: 791-799.

Chakraborty M, Kotecha S, Adappa R, et al. Safety and efficacy of high-flow nasal cannula therapy in preterm infants: a systematic review and meta-analysis. Eur Respir J 2015; 46: Suppl. 59, PA1871.

Roberts CT, Manley BJ, Dawson JA, et al. Nursing perceptions of high-flow nasal cannulae treatment for very preterm infants. J Paediatr Child Health 2014; 50: 806-810.

Shetty S, Rafferty G, Greenough A. Humidified high flow nasal cannula (HFFNC) and continuous positive airways pressure (CPAP) in infants with evolving bronchopulmonary dysplasia (BPD). Eur Respir J 2015; 46: Suppl. 59, PA1869.

Yoder BA, Stoddard RA, Li M, et al. Heated, humidified high-flow nasal cannula versus nasal CPAP for respiratory support in neonates. Pediatrics 2013; 131: e1482-e1490.

Roberts CT, Owen LS, Manley BJ, et al. A multicentre, randomised controlled, non-inferiority trial, comparing high flow therapy with nasal continuous positive airway pressure as primary support for preterm infants with respiratory distress (the HIPSTER trial): study protocol. BMJ Open 2015; 5: e008483.

Saint G, Smyth R, Flanagan B, et al. Investigation of the innate antiviral response to respiratory syncytial virus. Eur Respir J 2015; 46: Suppl. 59, OA1991.

Fonseca A, Scott N, Strickland D, et al. Persistence of respiratory syncytial virus replication in lung dendritic cells. Eur Respir J 2015; 46: Suppl. 59, PA3624.

2015; 46: Suppl. 59, OA1990.

Boyd K, McIntosh E, Lewis S, et al. Cost-effective management of bronchiolitis in infants: $90 \%$ versus $94 \%$ oxygen saturation. Eur Respir J 2015; 46: Suppl. 59, OA1988.

Okolysheva N, Kisteneva L, Malinovskaya V, et al. Effect of recombinant $\alpha 2-\beta$-interferon therapy on virologic and immunologic characteristics by children at early age with acute respiratory viral infections. Eur Respir J 2015, 46: Suppl. 59, OA1989. 

Eur Respir J 2015; 46: Suppl. 59, PA3626.

98 Bjornson C, Chan P, Li A, et al. Palivizumab prophylaxis for respiratory syncytial virus (RSV) in infants with cystic fibrosis (CF) and respiratory illness hospitalizations. Eur Respir J 2015; 46: Suppl. 59, PA3625.

99 Korten I, Mika M, Gorgievski M, et al. Symptomatic rhinovirus infections are associated with a lower diversity of the nasopharyngeal microbiota in infants. Eur Respir J 2015; 46: Suppl. 59, OA1987.

100 Hirst R, Rutman A, Williams G, et al. Ciliary and epithelial abnormalities are features of primary ciliopathies. Eur Respir J 2015; 46: Suppl. 59, OA1992.

101 Loges NT, Frommer A, Hjeij R, et al. Immunofluorescence analysis and diagnosis of primary ciliary dyskinesia with radial spoke defects. Eur Respir J 2015; 46: Suppl. 59, OA1993.

102 Devaney R, Pasalodos S, Suri M, et al. Presentation and diagnostic delay in ataxia telangiectasia (A-T). Eur Respir J 2015; 46: Suppl. 59, PA3630.

103 van Mastrigt E, Zweekhorst S, Bol B, et al. Sphingolipids in tracheal aspirates of prematurely born infants with and without BPD. Eur Respir J 2015; 46: Suppl. 59, PA3620.

104 Zimmels S, Kelly A, Fleming L. Swallow aspiration and respiratory symptoms in normally developing children. Eur Respir J 2015; 46: Suppl. 59, PA3632.

105 Sun Y. Clinical characteristics of Chlamydia trachomatis respiratory tract infections in young infants in South Korea. Eur Respir J 2015; 46: Suppl. 59, PA3636.

106 Chiu C-Y, Wong K-S, Lai S-H, et al. Protein profiling of pleural fluid in guiding management of infectious parapneumonic effusion in children. Eur Respir J 2015; 46: Suppl. 59, PA3634.

107 Berraies A, Moussa C, Hamdi B, et al. Characteristics and outcomes of pulmonary hydatid disease in children: about 70 cases. Eur Respir J 2015; 46: Suppl. 59, PA3631.

108 Lambrecht BN, Hammad H. The immunology of asthma. Nat Immunol 2015; 16: 45-56.

109 Teach SJ, Gill MA, Togias A, et al. Preseasonal treatment with either omalizumab or an inhaled corticosteroid boost to prevent fall asthma exacerbations. J Allergy Clin Immunol 2015; 136: 1476-1485.

110 Pérez-Losada M, Castro-Nallar E, Bendall ML, et al. Dual transcriptomic profiling of host and microbiota during health and disease in pediatric asthma. PLoS One 2015; 10: e0131819.

111 Teo SM, Mok D, Pham K, et al. The infant nasopharyngeal microbiome impacts severity of lower respiratory infection and risk of asthma development. Cell Host Microbe 2015; 17: 704-715.

112 Vasbinder E, Goossens L, Janssens H, et al. E-monitoring of asthma therapy to improve compliance in children (E-MATIC). Eur Respir J 2015; 46: Suppl. 59, OA4771.

113 Van den Wijngaart L, Roukema J, Merkus P. A virtual asthma clinic for children: improved asthma control, less hospital visits. Eur Respir J 2015; 46: Suppl. 59, OA4777.

114 Morton R, Everard M, Elphick H. Randomised control trial to investigate whether electronic adherence monitoring with reminder alarms and feedback can improve clinical outcomes in childhood asthma. Eur Respir J 2015; 46: Suppl. 59, OA4772.

115 Jochmann A, Nagakumar P, Hall P, et al. Improvement in asthma control and airway inflammation during a period of electronic monitoring. Eur Respir J 2015; 46: Suppl. 59, OA4775.

116 Voorend-van Bergen S, Beerthuizen T, Van den Hout W, et al. Cost-effectiveness of FeNO- and web-based monitoring in pediatric asthma management. Eur Respir J 2015; 46: Suppl. 59, OA4776.

117 Howard S, Lang A, Youle C, et al. Exploring the attitudes of adolescents with asthma towards monitoring and sharing of data on their inhaler use. Eur Respir J 2015; 46: Suppl. 59, OA4773.

118 Zhao J, Zhai YK, Zhu WJ, et al. Effectiveness of telemedicine for controlling asthma symptoms: a systematic review and meta-analysis. Telemed J E Health 2015; 21: 484-492.

119 Antón-Pacheco JL, Luna-Paredes C, García Hernández G, et al. Long-term outcomes and quality of life in children with airway obstruction treated by metallic stents. Eur Respir J 2015; 46: Suppl. 59, PA1344.

120 Krivec U, Aldeco M, Kotnik Pirs A, et al. Therapeutic airway procedures during flexible bronchoscopy in infants and children. Eur Respir J 2015; 46: Suppl. 59, PA1349.

121 Douros K, Kremmydas G, Grammeniatis V, et al. Helical CT scan to diagnose tracheomalacia in children. Eur Respir J 2015; 46: Suppl. 59, PA1345.

122 Fasseeh N, Gaafar A, Ashoush B. Subglottic hemangiomas in infants admitted to Alexandria university hospitals: clinical characteristics, assessment and management. Eur Respir J 2015; 46: Suppl. 59, PA1347.

123 Moreno M, Castillo-Corullón S, Pérez-Ruiz E, et al. Spanish multicenter study of morbidity and pathogenic role of tracheal bronchus in pediatric patients. Eur Respir J 2015; 46: Suppl. 59, PA1348.

124 Walker L, Scott A, Kansra S. Does physician decision to initiate antibiotics based on bronchoscopy findings correlate with bronchoalveolar lavage (BAL) results? Eur Respir J 2015; 46: Suppl. 59, PA1352.

125 Benzrath S, Schlegtendal A, Brinkmann F, et al. Dyspnoea due to exercise-induced dysfunctional breathing frequent entity in adolescents but poorly understood? Eur Respir J 2015; 46: Suppl. 59, PA1346.

126 Saguitaah M, Rémi G, Duboibaudry C, et al. Early following up of gas trapping with computed tomography during normal breathing in infant with cystic fibrosis. Eur Respir J 2015; 46: Suppl. 59, PA1294.

127 Stahl M, Wielpütz M, Gräber S, et al. MBW and MRI as sensitive markers of stable CF lung disease and at exacerbation in children and adolescents. Eur Respir J 2015; 46: Suppl. 59, OA1439. 